\title{
Article \\ Anti-Inflammatory Activity of Oat Beta-Glucans in a Crohn's Disease Model: Time- and Molar Mass-Dependent Effects
}

\author{
Ewa Żyła ${ }^{1}$, , Katarzyna Dziendzikowska ${ }^{1, * \mathbb{D}}$, Dariusz Kamola ${ }^{2}$, Jacek Wilczak ${ }^{2}$, Rafał Sapierzyński ${ }^{3} \mathbb{D}^{\text {, }}$ \\ Joanna Harasym ${ }^{4,5}$ (D) and Joanna Gromadzka-Ostrowska ${ }^{1}$ (D)
}

1 Department of Dietetics, Institute of Human Nutrition Sciences, Warsaw University of Life Sciences, Nowoursynowska 159c, 02-776 Warsaw, Poland; ewa_zyla@sggw.pl (E.Ż.); joanna_gromadzka_ostrowska@sggw.edu.pl (J.G.-O.)

2 Department of Physiological Sciences, Institute of Veterinary Medicine, Warsaw University of Life Sciences, Nowoursynowska 159, 02-776 Warsaw, Poland; dariusz_kamola@sggw.edu.pl (D.K.); jacek_wilczak@sggw.edu.pl (J.W.)

3 Department of Pathology and Veterinary Diagnostics, Institute of Veterinary Medicine, Warsaw University of Life Sciences, Nowoursynowska 159, 02-776 Warsaw, Poland; rafal_sapierzynski@sggw.edu.pl

4 Adaptive Food Systems Accelerator-Research Centre, Wrocław University of Economics, Komandorska 118/120, 53-345 Wrocław, Poland; joanna.harasym@ue.wroc.pl

5 Department of Biotechnology and Food Analysis, Wrocław University of Economics, Komandorska 118/120, 53-345 Wrocław, Poland

* Correspondence: katarzyna_dziendzikowska@sggw.edu.pl; Tel.: +48-22-593-7033

check for updates

Citation: Żyła, E.; Dziendzikowska, K.; Kamola, D.; Wilczak, J.;

Sapierzyński, R.; Harasym, J.;

Gromadzka-Ostrowska, J. AntiInflammatory Activity of Oat BetaGlucans in a Crohn's Disease Model: Time- and Molar Mass-Dependent Effects. Int. J. Mol. Sci. 2021, 22, 4485. https://doi.org/ijms22094485

Academic Editor: Alfredo Papa

Received: 1 April 2021

Accepted: 23 April 2021

Published: 25 April 2021

Publisher's Note: MDPI stays neutral with regard to jurisdictional claims in published maps and institutional affiliations.

Copyright: (c) 2021 by the authors. Licensee MDPI, Basel, Switzerland. This article is an open access article distributed under the terms and conditions of the Creative Commons Attribution (CC BY) license (https:/ / creativecommons.org/licenses/by/ $4.0 /)$.

\begin{abstract}
Background: The incidence of Crohn's disease (CD) is increasing worldwide, and it has currently become a serious public health issue in society. The treatment of CD continues throughout a patient's lifetime, and therefore, it is necessary to develop new, effective treatment methods, including dietotherapy. The present study aimed to determine the effects of consumption of oat beta-glucans with different molar mass on colon inflammation (colitis) in the early stages of 2,4,6-trinitrobenzene sulfonic acid (TNBS)-induced CD in an animal model. Methods: Sprague-Dawley rats (control and TNBS-induced CD) were divided into three dietary groups and fed for 3 days (reflecting acute inflammation) or 7 days (reflecting remission) with a feed containing $1 \%$ low ( $\beta \mathrm{Gl}$ ) or high ( $\beta \mathrm{Gh}$ ) molar mass oat beta-glucan or a feed without this polysaccharide. The level of colon inflammatory markers and the expression of cytokines and their receptor genes were measured by ELISA and RT-PCR methods, respectively. Results: Acute inflammation or remission (3 or 7 days after TNBS administration, respectively) stages of experimentally induced CD were characterized by an increase in the level of inflammatory markers (IL-1, IL-6, IL-10, IL-12, TNF- $\alpha$, CRP, MPO, COX, and PGE2) and the disruption of some cytokine signaling pathways as well as macro- and microscopic changes of colon tissue. The consumption of oat beta-glucans reduced the level of inflammatory markers and recovered the signaling pathways and histological changes, with stronger effects of $\beta \mathrm{Gl}$ after 7 days of colitis. Conclusions: Dietary oat beta-glucans can reduce colitis at the molecular and organ level and accelerate CD remission.
\end{abstract}

Keywords: oat beta-glucan; Crohn's disease; cytokines; cytokine gene expression

\section{Introduction}

Inflammatory bowel disease (IBD), in which ulcerative colitis (UC) and Crohn's disease (CD) are the two prevailing entities, is an important global public health concern with an increasing incidence in recent years [1,2]. IBD is a chronic idiopathic inflammatory disorder of the gastrointestinal tract, resulting from a combination of genetic predisposition, environmental factors, and inappropriate immune response to the gut microbiota [3].

Epidemiological data show that CD is mainly a disease occurring in developed countries, and the number of cases has been increasing rapidly in the last few decades $[4,5]$. 
The pathological process of $\mathrm{CD}$ begins in the mucosa, but over time, $\mathrm{CD}$ may spread to the intestinal wall along its entire surface. The disease is usually segmental, but inflammatory changes may affect the entire digestive tract, from the mouth to the rectum [6]. Chronic inflammation can result in complications such as fistulas, abscesses, or intestinal strictures. The course of $C D$ is characterized by periods of exacerbation and remission. During exacerbation, there is an increased, abnormal stimulation of immune cells, which intensifies the synthesis and / or secretion of pro-inflammatory factors, e.g., cytokines such as TNF- $\alpha$ and Il-1. The main objectives of CD therapy are to reduce inflammation in the gut (induction of remission) and to prevent relapse (maintenance therapy). Another option is nutritional treatment during the early stages of $\mathrm{CD}$ by using plant-origin compounds with potent anti-inflammatory properties, similar to pharmacological treatment $[7,8]$. Such compounds include beta-glucans and other polysaccharides found in cereal grains.

Beta-glucans are a group of dietary fibers composed of D-glucose monomers linked by mixed 1,$3 ; 1,4$; or 1,6 $\beta$-glycosidic bonds; they are naturally found in the cell wall of fungi, yeast, seaweed, and higher plants such as cereals. Depending on the botanical origin, molar mass, spatial structure, and degree of purification, they can have different effects on the body [9]. Numerous studies have shown that beta-glucans of various origins can significantly stimulate several types of immune responses toward microorganisms and toxic and mutagenic factors [10-13].

To date, few research studies have investigated the health effects of oat beta-glucans with different molar mass, especially in the context of ongoing inflammatory mechanisms [14-16]. This prompted us to compare the effects of the pure fraction of low and high molar mass oat beta-glucans on colon inflammation in Sprague-Dawley rats as a model that corresponds to human CD. In the present study, we used highly purified oat 1,3/1,4-beta-D-glucan in two substantially different molar mass fractions. This study aimed to determine the molecular mechanisms involved during colon inflammation at the early stages of $\mathrm{CD}$ and during the administration of a diet containing oat beta-glucans with different molar mass.

\section{Results}

\subsection{Feed Intake and Body Weight}

Within 3 days after $0.9 \% \mathrm{NaCl}$ or TNBS administration, the feed intake was at the similar level in control and colitis rats, except that the $\mathrm{C} \beta \mathrm{G}$ - group that showed significantly lower feed consumption. The feed intake in $C \beta G l+$ and $C \beta G h+$ rats was significantly higher than that in $\mathrm{C} \beta \mathrm{G}$ - rats. Feed intake 7 days after TNBS/ $\mathrm{NaCl}$ administration regardless of the type of feed consumed was at the similar level (Figure 1).

The initial body weight of all 108 rats was similar, with a mean value of $414.0 \pm 1.29 \mathrm{~g}$. The final body weight after 3 days of TNBS or $0.9 \% \mathrm{NaCl}$ administration decreased in all control and colitis groups, whereas after 7 days, the final body weight in all control groups increased slightly regardless of nutritional intervention from $8 \mathrm{~g}(\mathrm{H} \beta \mathrm{Gh}+)$ or $14 \mathrm{~g}(\mathrm{H} \beta \mathrm{G}-)$ to $18 \mathrm{~g}(\mathrm{H} \beta \mathrm{Gl}+)$ as compared to their initial body weight. The final body weight of rats with experimentally induced colitis 7 days after TNBS/ $\mathrm{NaCl}$ administration was lower regardless of dietary regime (Table 1 ).

Table 1. Final body weight (mean \pm SE) ( $n=8$ in each group).

\begin{tabular}{ccccccc}
\hline \multirow{2}{*}{ Time (days) } & \multicolumn{3}{c}{ Healthy Group } & \multicolumn{3}{c}{ Colitis Group } \\
\cline { 2 - 7 } & $\mathbf{H} \boldsymbol{\beta G}-$ & $\mathbf{H} \boldsymbol{\beta G l +}$ & $\mathbf{H} \boldsymbol{\beta G h +}$ & $\mathbf{C} \beta \mathbf{G}-$ & $\mathbf{C} \beta \mathbf{G l +}$ & $\mathbf{C} \beta \mathbf{G h}+$ \\
\hline 3 & $327.63 \pm 6.64$ & $326.38 \pm 4.51$ & $333.25 \pm 3.65$ & $304.5 \pm 9.22$ & $322.13 \pm 9.86$ & $317.5 \pm 8.32$ \\
7 & $427.75 \pm 5.14$ & $431.5 \pm 5.43$ & $422.0 \pm 3.96$ & $406.25 \pm 19.48$ & $403.5 \pm 11.5$ & $397.88 \pm 7.48$ \\
\hline
\end{tabular}




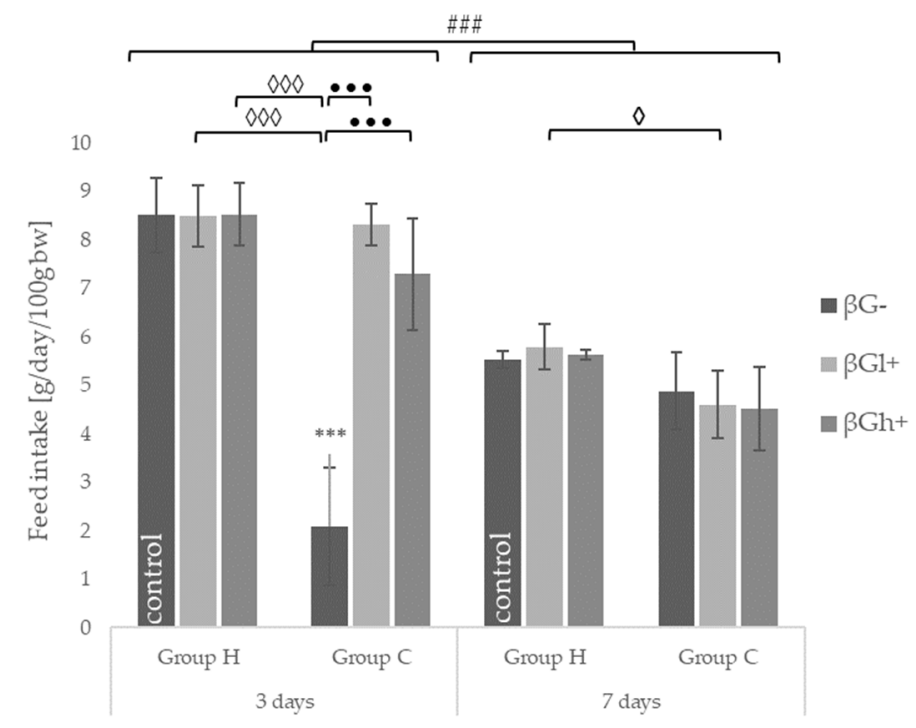

Figure 1. Feed intake 3 and 7 days after TNBS or $0.9 \% \mathrm{NaCl}$ administration (mean $\pm \mathrm{SE})(\mathrm{n}=8$ in each group). Significantly different from the control group ${ }^{* * *} p<0.001$; in the same experimental groups with regard to beta-glucans treatment $\bullet \bullet \bullet<0.001$; between the experimental groups with regard to beta-glucans treatment $\diamond p<0.05, \diamond \diamond \diamond p<0.001$; in the same experimental groups with regard to beta-glucan treatment at different time points \#\#\# $p<0.001$ (two-way ANOVA with Tukey's post-hoc test).

\subsection{Macroscopic and Microscopic Changes}

No macroscopic changes were found in the colon (score of mucosal damage $=0$ ) in the control healthy rats without intestinal inflammation both after 3 or 7 days, regardless of the type of nutritional intervention or its absence. Macroscopic changes of colon mucosa from C $\beta$ G- rats 3 and 7 days after TNBS administration confirmed severe local inflammation estimated as a median score of 3 or 2, respectively (Table 2), which was manifested by mucosal edema and minor bleeding (Figure 2(A1) left and right side, respectively). At the same time points in rats from the $C \beta G l+$ and $C \beta G h+$ groups, there was a reduction in the above-mentioned mucosal changes: median score $=2$ in both cases (Table 2, Figure 2(B1,C1) left and right side, respectively).

Table 2. Score of macroscopic damages of the colon mucosa. Damage score (0-4). Data are expressed as medians ( $\mathrm{n}=8$ in each group).

\begin{tabular}{ccccccc}
\hline \multirow{2}{*}{$\begin{array}{c}\text { Time } \\
\text { (days) }\end{array}$} & \multicolumn{3}{c}{ Healthy Group } & \multicolumn{3}{c}{ Colitis Group } \\
\cline { 2 - 7 } & $\mathrm{H} \beta \mathrm{G}-$ & $\mathrm{H} \beta \mathrm{Gl}+$ & $\mathrm{H} \beta \mathrm{Gh}+$ & $\mathrm{C} \beta \mathrm{G}-$ & $\mathrm{C} \beta \mathrm{Gl}+$ & $\mathrm{C} \beta \mathrm{Gh}+$ \\
\hline 3 & 0 & 0 & 0 & 3 & 2 & 2 \\
7 & 0 & 0 & 0 & 2 & 2 & 2 \\
\hline
\end{tabular}

Histological analysis of macroscopically altered colon sections confirmed extensive inflammation in the tissue of rats from the $\mathrm{C} \beta \mathrm{G}$ - group (Figure 2(A2) left and right side). The lesions were trans-wall in nature, covering not only the mucosa but also the submucosal layer, which is a characteristic of $\mathrm{CD}$. Microscopic changes included inflammatory changes together with infiltration of lymphocytes and granulocytes and focal or extensive ulceration, which was confirmed by a median score of 5 (3 days) or 3 (7 days) (Table 3, Figure 2(B2) left and right side, respectively). The consumption of feed supplemented with both betaglucans did not reduce these changes after 7 days (Table 3, Figure 2(C2) right side), whereas after 3 days, the general microscopic score was significantly reduced in the $C \beta G h+$ group (Table 3, Figure 2(C2) left side). In the control groups, no microscopic damages in this part 
of the colon (after 3 days) or minor changes (after 7 days) were found (Table 3, Figure 2(D2) left and right side, respectively).

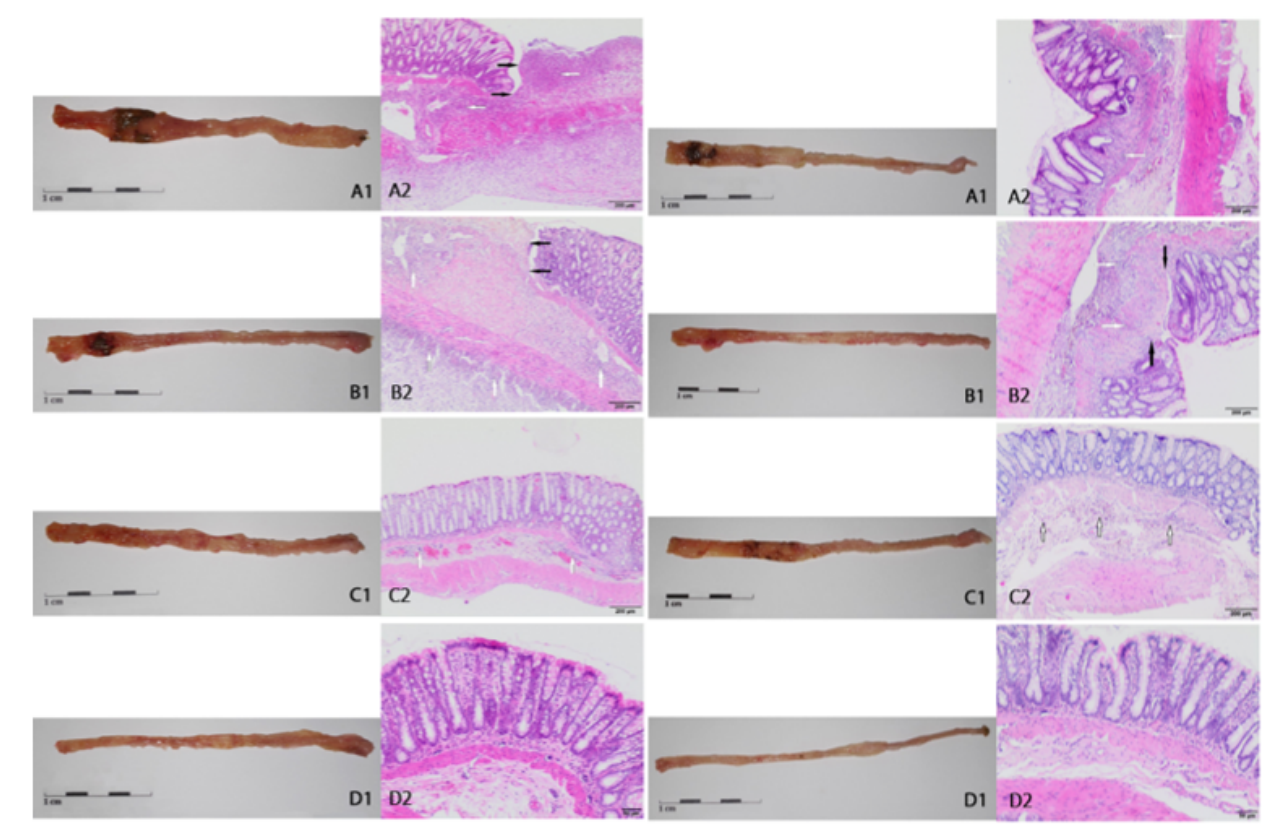

Figure 2. Macroscopic and microscopic changes in the descending colon 3 (left side) and 7 (right side) days after TNBS administration. (A1,A2): colitis C $\beta$ G- groups; (B1,B2): colitis $C \beta G 1+$ groups; $(\mathbf{C} 1, \mathbf{C} 2)$ : colitis $C \beta G$ + groups; $(\mathbf{D} 1, \mathbf{D} 2)$ : health HC $\beta$ G- groups. White arrows indicate multifocal/diffuse inflammatory infiltration of the mucosa and/or submucosa of varying severity, black arrows indicate margins of ulceration. Hematoxylin-eosin staining, magnification: (B2) left side and (C2) left side-4x; (A2) both sides, (B2) right side, (C2) right side-10x; (D2) both sides—20x. Various magnifications were used to better visualization of different lesions.

Table 3. Score of microscopic damages of the colon mucosa and submucosa. Damage score (0-5). Data are expressed as medians ( $\mathrm{n}=8$ in each group).

\begin{tabular}{ccccccc}
\hline \multirow{2}{*}{$\begin{array}{c}\text { Time } \\
\text { (days) }\end{array}$} & \multicolumn{3}{c}{ Healthy Group } & \multicolumn{3}{c}{ Colitis Group } \\
\cline { 2 - 7 } & $\mathbf{H} \beta \mathrm{G}-$ & $\mathbf{H} \beta \mathrm{Gl+}$ & $\mathbf{H} \beta \mathrm{Gh}+$ & $\mathbf{C} \beta \mathrm{G}-$ & $\mathbf{C} \beta \mathrm{Gl+}$ & $\mathbf{C} \beta \mathrm{Gh}+$ \\
\hline 3 & 0 & 0.5 & 0.5 & 5 & 5 & 3.5 \\
7 & 1 & 1 & 1 & 3 & 3 & 3 \\
\hline
\end{tabular}

\subsection{Levels of C-Reactive Protein and Selected Cytokines in the Colon Tissue}

The levels of selected inflammatory markers were determined to describe the immune response of colon tissue to the induction of inflammation. Differences were observed in the effect of dietary intervention type (with two different fractions of oat beta-glucans) depending on the duration of the experiment ( 3 and 7 days after TNBS rectal administration).

Compared to the control group ( $\mathrm{H} \beta \mathrm{G}-$ ), the induction of inflammation by the rectal administration of TBNS without nutritional intervention (group $C \beta G-$ ) at both time points ( 3 and 7 days) caused a significant increase in the levels of all pro-inflammatory cytokines (IL-1, IL-6, IL-12, and TNF- $\alpha$ ) and C-reactive protein (CRP), whereas a decrease in the level of the anti-inflammatory cytokine IL-10 was observed. The increase in some proinflammatory cytokines (TNF- $\alpha$, IL-1) and the decrease in IL-10 level in the colon wall were significantly greater at 3 days, whereas the increase in IL-12 was much higher at 7 days. The colon levels of CRP and IL-6 were comparable at 3 and 7 days. In the colitis groups, the consumption of feed containing oat beta-glucans resulted in a significant decrease in the level of all measured pro-inflammatory cytokines and an increase in the level of anti-inflammatory cytokine. Two-way ANOVA confirmed that these effects depended on both the molar mass of beta glucans and the length of the animal's feeding period. 
The CRP level in the colon wall after 3 days of TNBS administration did not change significantly in the groups of animals consuming feed with the addition of both fractions of beta-glucans, while a significant reduction in the CRP level was found after 7 days, especially in animals from the $\mathrm{C} \beta \mathrm{Gl}+$ group (Figure 3A). The IL-1 level was significantly reduced in the first period of colitis development (3 days) in both the $C \beta \mathrm{Gh}+$ and $\mathrm{C} \beta \mathrm{Gl}+$ groups. In the next period of inflammation development (7 days), this reduction was significantly greater, especially in the $\mathrm{C} \beta \mathrm{Gl}+$ group (Figure $3 \mathrm{~B}$ ). A significant reduction was also observed in the level of IL- 6 in the colon wall at both time points, with the reduction being greater after 3 days of ongoing inflammation in the $C \beta G l+$ group. Seven days post TNBS administration, the $C \beta G h+$ and $C \beta G l+$ groups showed a similar level of this pro-inflammatory cytokine (Figure $3 \mathrm{C}$ ). It was also found that TNF- $\alpha$ level measured 3 days after administration of TNBS was lower in group $\mathrm{C} \beta \mathrm{Gl}+$, whereas 7 days after the induction of colitis, an increase in the TNF- $\alpha$ level was observed in the $C \beta G$ h + group (Figure 3D). The IL-12 level was also significantly decreased compared to that in animals, which did not receive beta-glucans in their feed, with a greater level of reduction at 7 days regardless of the molar mass of beta-glucan administered. In addition, the $C \beta G h+$ group and the $C \beta G l+$ group showed a greater reduction after 3 days and 7 days of ongoing inflammation, respectively (Figure $3 \mathrm{E}$ ). Contrasting changes were found in the level of the anti-inflammatory cytokine IL-10, which increased significantly both after 3 and 7 days without a significant difference between the groups consuming feed with low or high molar mass beta-glucans (Figure 3F).

In the control groups, the levels of pro- and anti-inflammatory cytokines did not change significantly at both time points and in relation to the molar mass of beta-glucans.

\subsection{Other Selected Inflammatory Markers}

Additionally, we investigated the colon concentration of two enzymes associated with arachidonic acid transformation, which are involved in the inflammatory process: cyclooxygenase (COX) and myeloperoxidase (MPO). The levels of prostaglandin E2 (PGE2) and thromboxane A2 (TXA2) in the colon tissue were also analyzed.

The levels of COX, MPO, and PGE2 in the colon tissue significantly increased in animals with induced colitis fed with feed without beta-glucans (C $\beta G-v s$. H $\beta G-)$ at both time points; however, a significantly greater increase in COX levels was found at 7 days, while a significantly greater increase in MPO and PGE levels was observed at 3 days after TNBS administration.

The levels of COX, MPO, and PGE2 were significantly decreased in colitis rats fed with feed containing beta-glucans compared to rats with colitis fed with feed without beta-glucans at both time points. Rats from the $\mathrm{C} \beta \mathrm{Gl}+$ group showed a greater reduction in COX and PGE2 concentrations, rats from the $\mathrm{C} \beta \mathrm{Gl}+$ and $\mathrm{C} \beta \mathrm{Gh}+$ groups showed a greater reduction in MPO concentration (Figure $4 \mathrm{a}-\mathrm{c}$, respectively). The addition of low and high molar mass beta-glucans reduced the MPO level to the value detected in the control group ( $7 \mathrm{C} \beta \mathrm{Gl}+$ and $7 \mathrm{C} \beta \mathrm{Gh}+\mathrm{vs}$. $7 \mathrm{H} \beta \mathrm{G}-)$. The consumption of feed with low molar mass beta-glucans also reduced the COX level in colitis rats to the value detected in the control group ( $7 \mathrm{C} \beta \mathrm{Gl}+\mathrm{vs}$. $7 \mathrm{H} \beta \mathrm{G}$-). The TXA2 level in the colon did not significantly change at 3 days after TNBS administration, whereas at 7 days, the level of TXA2 significantly increased in the $C \beta G$ - group as compared to that in the $\mathrm{H} \beta \mathrm{G}$ - group. The consumption of feed containing both fractions of beta-glucans retained the TXA2 level in colitis rats to the value detected in the control group (Figure $4 \mathrm{~d}$ ).

In the control groups, the levels of COX, MPO, PGE2, and TXA2 did not change significantly depending on both the inflammation and the dietary beta-glucan fractions (Figure $4 a-c)$. 


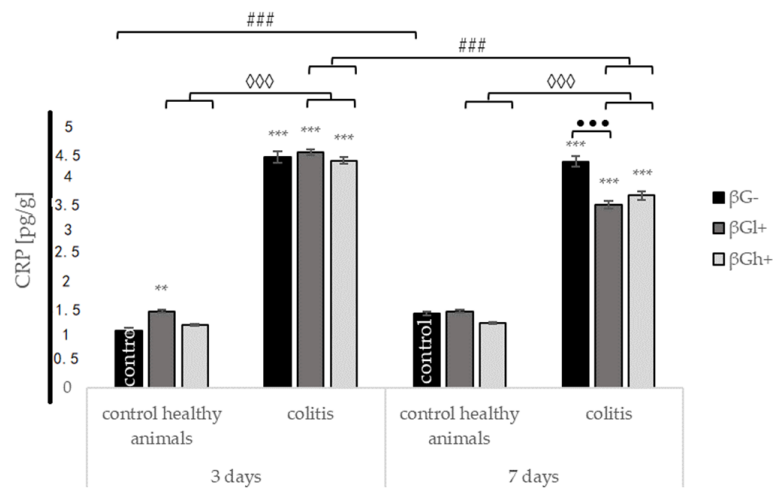

(a)

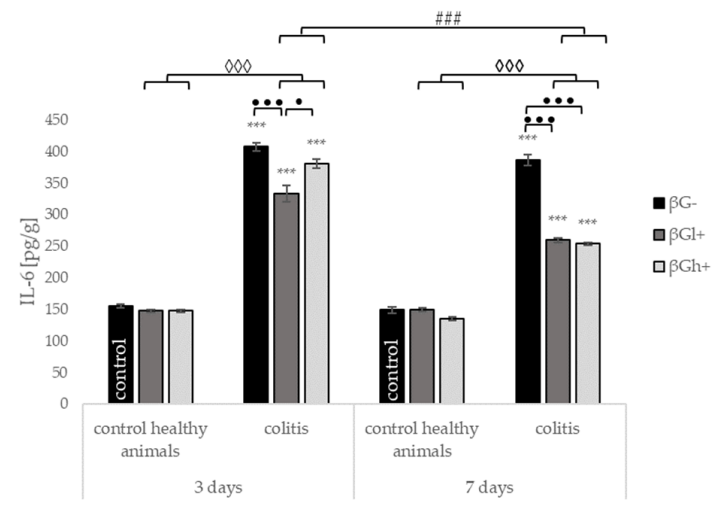

(c)

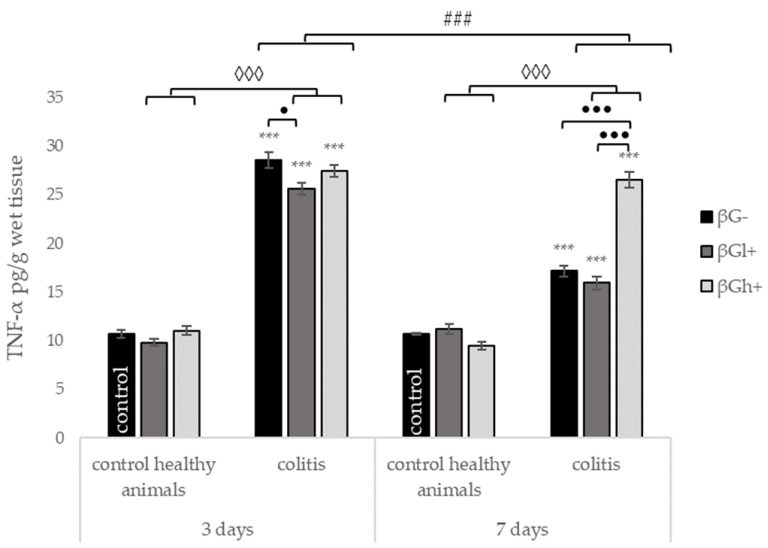

(e)

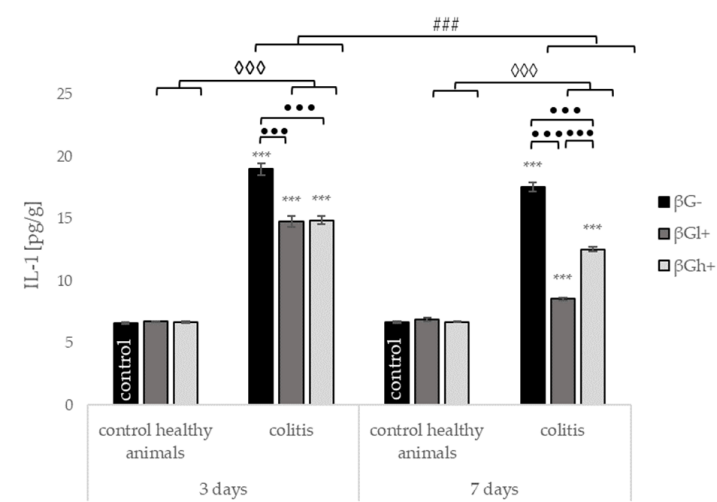

(b)

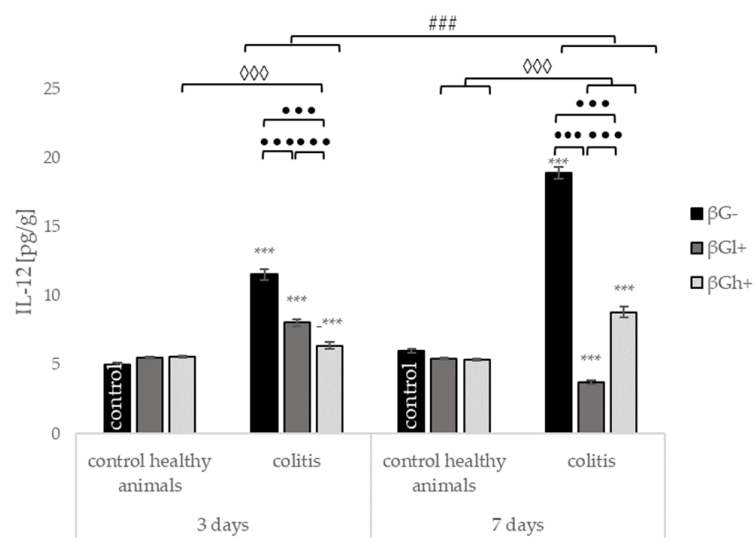

(d)

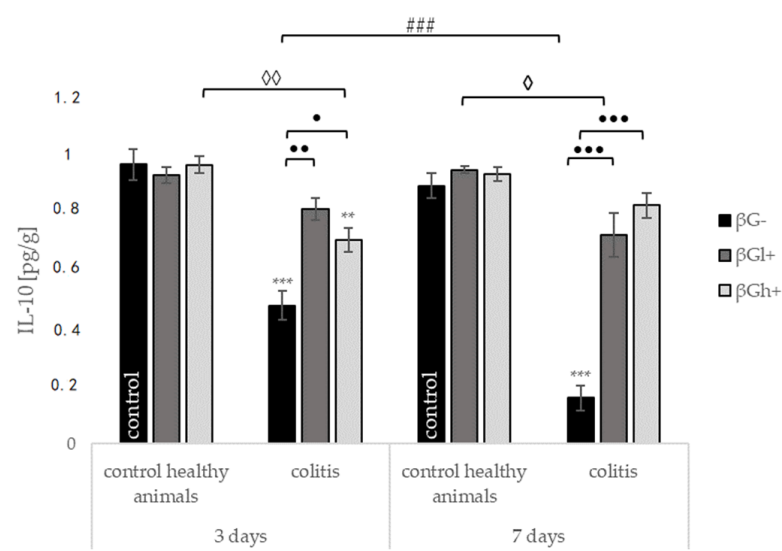

(f)

Figure 3. The effect of the development of colitis and dietary intervention on the level of C-reactive protein and cytokines in the colon tissue: (a) C-reactive protein (CRP); (b) interleukin 1 (IL-1); (c) interleukin 6 (IL-6); (d) interleukin 12 (IL-12); (e) tumor necrosis factor $\alpha$ (TNF- $\alpha$ ) and (f) the interleukin 10 (IL-10) protein level (mean \pm SE) ( $n=8$ in each group). Significantly different from the control group ${ }^{* *} p<0.01,{ }^{* * *} p<0.001$; in the same experimental groups with regard to beta-glucans treatment $\bullet p<0.05, \bullet \bullet<0.01, \bullet \bullet p<0.001$; between the experimental groups with regard to beta-glucans treatment $\diamond p<0.05, \diamond \diamond p<0.01, \diamond \diamond \diamond p<0.001$; in the same experimental groups with regard to beta-glucan treatment at different time points \#\#\# $p<0.001$ (two-way ANOVA with Tukey's post-hoc test). 


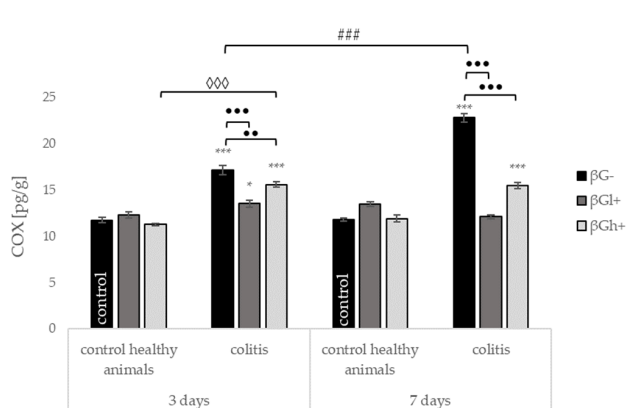

(a)

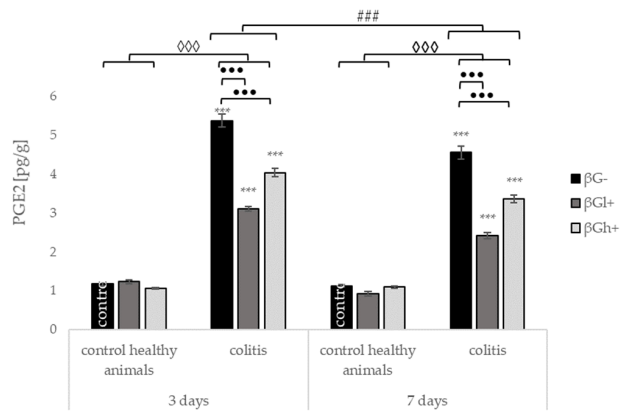

(c)

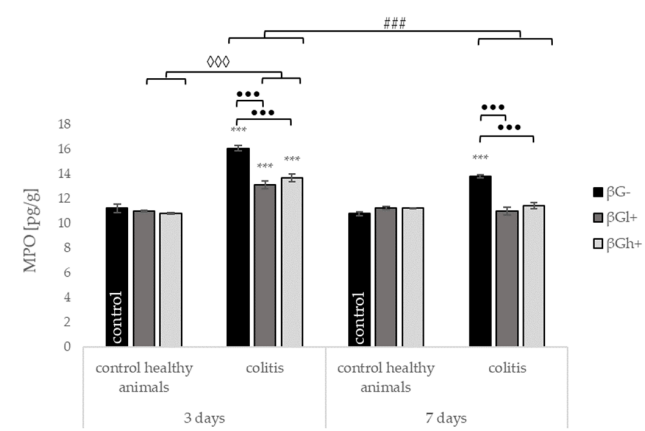

(b)

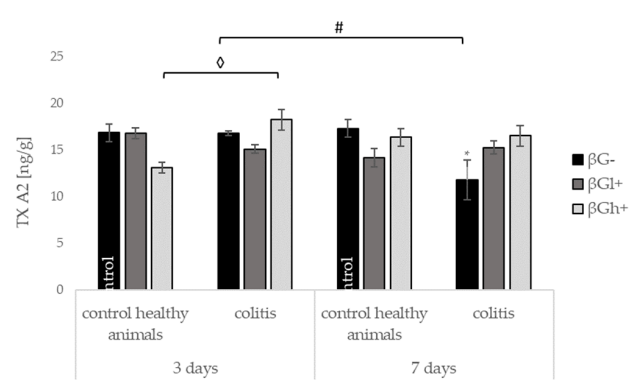

(d)

Figure 4. The effect of the development of colitis and dietary intervention on the level of selected immunological markers in the colon tissue: (a) total cyclooxygenase (COX); (b) myeloperoxidase (MPO); (c) prostaglandin E2 (PGE2); and (d) thromboxane A2 (TXA2) protein level (mean \pm SE) $\left(\mathrm{n}=8\right.$ in each group). Significantly different from the control group ${ }^{*} p<0.05,{ }^{* * *} p<0.001$; in the same experimental groups with regard to beta-glucans treatment $\bullet \bullet p<0.01, \bullet \bullet \bullet<0.001$; between experimental groups with regard to beta-glucans treatment $\diamond p<0.05, \diamond \diamond \diamond p<0.001$; in the same experimental groups with regard to beta-glucan treatment at different time points \# $p<0.05$, \#\#\# $p<0.001$ (two-way ANOVA with Tukey's post-hoc test).

\subsection{Expression of Genes Encoding Inflammatory Cytokines and their Receptors}

To elucidate the observed beneficial effects for both fractions of oat beta-glucans, the underlying molecular mechanisms were analyzed using the pathway-focused RT-PCR array for 50 different genes that encode inflammatory cytokines and their receptors expressed in the colon tissue. Our study also aimed to clarify whether the studied fractions of oat beta-glucans have different effects on the selected anti- and pro-inflammatory markers and whether this relationship is time-dependent.

The analysis was performed using the Rat Inflammatory Cytokines and Receptors array. The results showed that 3 days after TNBS administration, which corresponds to the acute colitis stage, of the 47 analyzed genes, 23 were up-regulated in the colitis group (C $\beta \mathrm{G}$-) as compared to that in the healthy control group (H $\beta \mathrm{G}-)$. The up-regulated genes included those encoding interleukins and their receptors: Il1a, Il1b, Il11, Il17a, Il17f, Il21, Il33, Illr1, Illrn, Il2rb, Il2rg, Il6r, and Il10ra, and other inflammatory mediators: Ifng, Lta, Ltb, Mif, Osm, Pf4, Spp1, Tnf, Tnfsf11, and Tnfsf14. The supplementation of high molecular weight beta-glucan to the animal feed (C $\beta G h+$ group) up-regulated the expression of the Il5, Il13, and Tnfsf10, Lta and Bmp2 genes and down-regulated the expression of the Il1a, Il1b, Il11, Il17a, Il17b, Il17f, Il1r1, Il2rg, Il6r, Il10ra, Osm, Spp1, Tnf, and Tnfsf11 genes. The efficient colitis lowering effect was also observed in animals fed a diet supplemented with low molecular weight beta-glucan ( $\mathrm{C} \beta \mathrm{Gl}+$ group). Genes encoding Ifng, Il3, and Il13 were up-regulated, whereas those encoding Il1b, Il17a, Il21, Il5ra, Cd40lg, Osm, Tnf, Tnfsf11, and Tnfsf14 were down-regulated (Supplementary Materials, Table S1).

After 7 days of colitis induction, the expression of 18 genes, namely Il1a, Il1b, Il3, Il4, Il11, Il17a, Il17f, Il1r1 Il1rn, Il2rb, Il10ra, Faslg, Ifng, Mif, Osm, Pf4, Spp1, and Tnfsf4, was up-regulated whereas the expression of the Bmp2, Cd40lg, Lta, and Tnfsf11 genes was 
down-regulated in the $C \beta G$ - group as compared to that in the $\mathrm{H} \beta \mathrm{G}$ - control group. In this stage of colitis, food intake with $\beta \mathrm{Gh}(\mathrm{C} \beta \mathrm{Gh}+$ group) up-regulated the expression of the $I l 13, I l 21, I l 27$, and Lta genes and down-regulated the expression of the Il1a, Il11, and Il17a genes. Moreover, the supplementation of low molecular weight beta-glucan to the animal feed (C $\beta G \mathrm{Gl}+$ group) up-regulated the $I l 21$ and $L t a$ genes expression and down-regulated the expression of the Il3, Il11, Osm, and Spp1 genes (Supplementary Materials, Table S1).

\section{Discussion}

The prevalence of Crohn's disease (CD) is increasing worldwide. $C D$ is a chronic disease belonging to the IBD group and is characterized by alternating inflammation exacerbation and remission periods $[17,18]$. As a result of the complex and poorly understood etiopathogenesis of $C D$, it is essential to better understand the immune mechanisms related to this disease and to develop new, effective therapeutic options, including the use of natural and bioactive food compounds. Therefore, in this study, we analyzed the effects of oat beta-glucans administration at two time points, 3 and 7 days after TNBS administration. The use of the TNBS-induced colitis model allowed assessing immunological parameters at various stages of development of inflammatory lesions in the colon of rats, which corresponded to $C D$ phases characterized by different severity levels in humans. Colitis induced by rectal administration of an ethanolic solution of TNBS, which is well described in the literature $[19,20]$, causes transmural changes with clinical symptoms and a histological presentation characteristic of CD in humans [21,22]. This colitis model is also suitable for studying cell signaling pathways [23] and for analyzing a wide spectrum of cytokines [21,24]. Ethanol from the rectally administered solution is responsible for the damage of the colon epithelium and mucosal barrier breakdown. Ethanol allows the interaction of picrylsulfonic acid (TNBS) with the colon proteins, and consequently, it causes local necrosis resulting from ROS-induced oxidative damage. Both substances act synergistically to induce a strong local immune response, with the infiltration of the colon wall by lymphocytes and granulocytes and secretion of pro-inflammatory cytokines [21].

Three days after TNBS administration, rats fed the feed without oat beta-glucan supplementation developed local acute inflammation, which is a characteristic of the active phase of CD [23]. Histological evaluation of the colon confirmed extensive transmural inflammation, including inflammation of the mucosa and submucosal layers, which are characteristics of CD [22]. Seven days after TNBS administration, these symptoms improved, indicating the onset of inflammatory remission. Food intake and body weight gain decreased drastically after 3 days from TNBS administration and increased significantly after 7 days. Morphological changes indicated an improvement in animal health. Colon inflammation is also evidenced by a significant increase in the level of CRP, which is a marker of inflammation and is significantly elevated in patients in the exacerbation phase of CD [25]. The concentrations of pro-inflammatory cytokines (Il-1, Il-6, Il-12, and TNF- $\alpha$ ) are also increased. The level of these cytokines increases in a time-dependent manner and confirms differences in the severity of colitis after 3 and 7 days of the ongoing process. The concentration of CRP and the cytokines Il- 1 and Il- 6 in the colon tissues were similar at both time points, which may be because the main signaling compound stimulating the synthesis of CRP is IL-6, while IL- 1 also stimulates the synthesis of other acute-phase proteins [26]. Additionally, the increased protein level of pro-inflammatory cytokines, e.g., Il-1, Il-6, and TNF- $\alpha$, causes a reduction in food intake as observed in our study and by Plata-Salaman (2001) [27].

After 7 days, rats with colitis had a significantly higher Il-12 level and a lower TNF- $\alpha$ protein level than those observed in control animals. The increase in IL-12 concentration after 7 days in animals fed control feed without beta-glucans may indicate the transition of the disease into a chronic form. This condition is a characteristic of both the TNBS-induced chronic inflammation model and the human CD, where the activity and proliferation of Th1 cells are increased due to an increase in IL-12 level [24]. In recent years, cytokine signaling pathways have been considered as a potential therapeutic target in IBD and in the 
treatment of autoimmune diseases such as $\mathrm{CD}[28,29]$. Several attempts have been made to use monoclonal antibodies binding to the IL-12 subunit [30]. In the present study, activation of the immune response was confirmed both in terms of the protein concentration and gene expression level of inflammatory cytokines. Analysis of the expression of genes involved in cascading immune responses in the colon wall showed a significant up-regulation of genes encoding cytokines and their receptors. These changes were observed especially for proinflammatory cytokines, particularly in the IL-1 and TNF families in colitis animals fed with control feed without beta-glucans. The results are in line with the findings of other authors who also confirmed the increase in the concentration of pro-inflammatory cytokines in animals with exogenous colitis [31,32]. Additionally, all these signaling molecules are known to be important factors in the pathophysiology of CD [33,34]. In the present study, we observed a significant effect of both colitis induction and beta-glucan supplementation on the gene expression level of pro-inflammatory cytokines, including Tnf, Il1a, Il1b, Il17a, and $I l 17 b$. A three-day supplementation with low molar mass oat beta-glucans reduced the expression of the $\operatorname{Tnf}$ gene. $\operatorname{Tnf}$ gene expression was significantly up-regulated in rats with acute colitis, but it was decreased in rats from the C $\beta G l+$ group. Cui et al. (2005) conducted a study on 29 patients with IBD and 18 healthy patients and showed an 8-fold increase in the intestinal mucosa TNF gene expression level in patients with CD and a higher level of TNF in their feces [35]. An excess concentration of TNF reduces the protective abilities of the intestinal epithelium and enhances the processes of intestinal tissue fibrosis [36], which may contribute to the development of neoplastic diseases. Therefore, our results indicate that beta-glucans appear to be effective agents that can prevent $\operatorname{Tnf}$ overexpression and protect against cancerogenesis.

Our results show that the concentration of the anti-inflammatory cytokine IL-10 at both time points was lower in colitis rats than in the control rats, with higher levels observed after 7 days. The anti-inflammatory effect of IL-10 is related to the synthesis of IL-RAP, an antagonist of this protein, which inhibits the synthesis of many pro-inflammatory cytokines such as IL-1, IL-6, and TNF- $\alpha$ [37]. The cytokine Il-10 also plays an important role in the maintenance of overactive intestinal immune cells [38]. Patients with CD are reported to have normal or high levels of IL-10 [39]. Mutations in the NOD2/CARD15 gene are associated with the development of CD [40,41]. The NOD2/CARD15 complex is an intracellular receptor for peptidoglycan, a component of the bacterial cell membrane, that activates the nuclear factor NF- $\mathrm{KB}$ and stimulates the MAPK protein kinase-related signaling pathway. The concentration of this protein increases along with the synthesis of pro-inflammatory cytokines TNF- $\alpha$ and IL- $1 \beta$ and other peptides with antibacterial activity. Under homeostatic conditions, the inflammatory response is inhibited by anti-inflammatory cytokines, including TGF- $\beta$ and IL-10. In CD, mutations in the NOD2/CARD15 gene block these mechanisms, leading to persistent inflammation in the gut wall [42].

Feeding colitis rats with feed containing oat beta-glucans led to a reduction of high levels of CRP, Il-6, and Il-12 in the colon wall after 7 days. This finding indicates an accelerated remission. These observed changes were also more pronounced in rats fed with feed containing low molar mass beta-glucans. Our previous study showed that feeding rats for 21 days after TNBS administration with food containing beta-glucan with a low molar mass resulted in a more significant reduction in the concentration of pro-inflammatory cytokines and eicosanoids and stronger activation of immune cells than that observed in animals fed with food containing high molar mass beta-glucans [43]. In the present study, the consumption of feed with the addition of beta-glucans, regardless of their molar mass, resulted in change in Il-10 level in rats with colitis to that observed in the appropriate control animals; this finding suggests the stimulation of anti-inflammatory mechanisms by these polysaccharides.

Beta-glucans might regulate the impaired immune response, which is a characteristic of colitis, which has been proven in both in vitro and in vivo studies. The incubation of lipopolysaccharide (LPS)-stimulated human macrophages with a mixture of oat or barley beta-glucans has been shown to reduce the expression of pro-inflammatory cytokines 
such as IL-8, IL-1 $\beta$, and IL-6 [44]. Additionally, the fungal beta-glucan inhibits dextran sulfate sodium (DSS)-induced ulcerative colitis and reduces the expression of inflammatory markers due to the suppression of the MAPK protein kinase signaling pathway [45]. Our previously published results have also shown that in rats with LPS-induced enteritis fed with feed containing low and high molar mass oat beta-glucan, the concentration of pro-inflammatory IL-1 and IL-12 was significantly reduced [14]. Liu et al. (2015) found a reduction in CD symptoms, including diarrhea and intestinal immune cell infiltration, as well as an increase in body weight gain and a reduction in inflammation in colitis rats fed with feed supplemented with oat beta-glucans. The proposed mechanism underlying this effect was based on beta-glucan-induced suppression of the IL- $1 \beta$ and IL- 6 genes and nitric oxide synthase (iNOS) [46]. In our previous study, we found a normalization of IL-10 concentration in rats with enteritis after supplementation with oat beta-glucans [14]. Similar results were reported by Crespo et al. (2017) in an in vitro study. The authors found reduced IL-10 synthesis by macrophages isolated from the blood of rats fed with feed supplemented with $5 \%$ fungal beta-glucans [47]. Another study showed that the effect of beta-glucans on the concentration of IL-10 secreted by LPS-stimulated dendritic cells depends on the method of this polysaccharide preparation, its solubility, and degree of aggregation [48].

On the basis of our previous study and the results of other authors, it seems that oat beta-glucans can stimulate the secretion of anti-inflammatory cytokines. They simultaneously inhibit the secretion of pro-inflammatory cytokines. The immunostimulatory effect of beta-glucan intake occurs due to its ability to activate intestinal mucosa immune cells, which results from the binding of these polysaccharides to a specific membrane TLR and/or Dectin-1 receptors. The activation of both types of receptors is different in the acute and remission phase of $C D$. Dietary intake of $\beta G l$ and $\beta G$ diminished colitis by the timedependent modulation of autophagy and apoptosis, which involved TLRs (TLR4, TLR5) and Dectin-1 receptor activation, with $\beta$ GI having a stronger effect on apoptosis (Caspase 3 expression) and $\beta$ Gh on autophagy (LC3B expression) [49]. Therefore, this might explain the difference in the effect of feeding with beta-glucans during 3 or 7 days after TNBS administration. Probably, the mechanism of the immunomodulatory effect of beta-glucans may also depend on its molar mass, which influences the severity of apoptosis and autophagy of colon epithelial cells. Our previous results show the most prominent reduction of mucosa and submucosa lymphocytes infiltration occurred after dietary supplementation with high molecular mass oat beta-glucan, while in the case of potential for the improvement of the cytokine gene and protein level, low molecular mass oat beta-glucan was more potent $[43,49]$. Beta-glucans with different molar mass activate different signaling pathways, and consequently, both forms reduce inflammation and accelerate remission, including restoration of integrity of the intestinal barrier [49]. High molar mass fractions of beta-glucan are known to form viscous gel-like dispersion with high adhesion properties. Long chains of glucose homopolymers coordinate water and reorganize charged side-branches of polymer resulting in a sticky surface easily bonding to any moisturized layer. By trapping beta-glucan linkages inside the gel, high molar mass fractions only tend to interact on a physical basis. Therefore, it is expected for feed containing high molar mass fractions of beta-glucan to adhere to the intestinal walls covering it. It can be expected that high molecular mass beta-glucan forms a protective coating on the internal intestinal wall, which improved tissue recovery potential and reduce the risk of secondary microbial infection. Meanwhile, the low molar mass fraction of beta-glucan forms light solutions where short chains are well distributed and dispersed, and due to low viscosity, beta-glucan is accessible for receptors to be reached. Once reaching and complementing the receptor, the bonded beta-glucan short polymeric chain induces transmission on metabolic pathways. Our results confirmed this hypothesis and may suggest that different molar mass oat beta-glucans could decrease inflammation by the downregulation of gene expression and the production of pro-inflammatory cytokines and other inflammatory signaling molecules. 
Our results suggest that oat beta-glucans can suppress inflammation by reducing gene expression, thereby reducing the secretion of pro-inflammatory cytokines and other inflammatory signaling molecules. Moreover, they have the ability to restore the balance between the levels of pro-inflammatory and anti-inflammatory cytokines. Since the consumption of food supplemented with the addition of oat beta-glucans not only decreased the gene expression of pro-inflammatory cytokines but also decreased their concentration, the action of these polysaccharides is considered to occur at both tissue and molecular levels.

In this study, we found that the concentration of other inflammatory markers in the colon wall, including MPO, significantly increased as compared to that in healthy animals with higher concentration at 3 days after TNBS administration. This indicates an initial acute inflammation that might be associated with neutrophil infiltration into the colon mucosa. A reduction in inflammation was achieved at 7 days after TNBS administration. Other studies have reported that the active phase of IBD shows a higher concentration of MPO than that observed in the remission phase [50]. Higher MPO concentrations are reported in patients with more severe forms of IBD [51] and in patients with other inflammatory conditions [52,53]. Feeding animals with feed containing beta-glucans, regardless of their molar mass, reduced the colon concentration of MPO and accelerated remission of colitis. Furthermore, we found that the COX and PGE2 concentration increased in colitis rats fed with the control feed. Three and 7 days after TNBS administration, rats fed with feed containing both low and high molar mass beta-glucan showed a significant reduction in the concentration of these two proteins, with the low molar mass beta-glucan exhibiting greater effectiveness.

Our results confirmed the strong immunomodulatory properties of chemically pure oat beta-glucan obtained by alkaline extraction from ground oat bran [54]. These formulations seem to be as strong as the beta-glucan formulations obtained from various fungal species, including yeast, which are already used in IBD treatment [9,55-57]. This hypothesis is confirmed by the results of the use of fungal beta-glucans as an "adjuvant", which strengthens the immune system of individuals with immune deficiencies or of patients undergoing anticancer therapy [58,59]. Oat beta-glucans have also been found to exhibit the same strong anti-tumor properties with cytotoxic effects on different human cancer cell lines $[60,61]$. Moreover, beta-glucans derived from oat induced trained immunity in monocytes and macrophages [62]. Our results showed that beta-glucan with a low molar mass has a particularly strong effect, which significantly accelerates the remission of $C D$ and reduces the severity of inflammation at the later stage of its development. The unique immunomodulatory properties of oat beta-glucans, particularly those of low molar mass, point to the possibility of using them as a bioactive ingredient for special medical purposes for people suffering from inflammatory bowel disease, especially CD. Despite the promising results, more research is needed to evaluate its effect on human beings effectively.

\section{Materials and Methods}

\subsection{Preparation of Deproteinated Oat Beta-Glucan Fractions}

High- and low-molar mass beta-glucan preparations were obtained from beta-glucan enriched oat fiber with methods described elsewhere [63]. Both high and low molar mass preparations were obtained due to patented methods [63,64]. Beta-glucan was isolated with alkaline water $(\mathrm{pH}=8.5 \mathrm{M} \mathrm{NaOH})$ and then deproteinated at an isoelectric point $(\mathrm{pH}=4.5)$, the protein precipitate was removed by centrifugation as described elsewhere [64]. Further purification was conducted using the enzymatic treatment of a group of proteolytic, peptidolytic, and amylolytic enzymes followed by subsequent enzyme protein precipitation at isoelectric points. Beta-glucan preparations purity was controlled with AOAC method 995.16 (Megazyme, Bray, Ireland). The molar mass of fractions was determined from intrinsic viscosity measurements of beta-glucan solutions and MarkHouwink equation application. The proteinaceous matter removal was controlled with SDS PAGE, Kjeldahl, and Lowry methods. The purity (Table 4) of high molar mass 
$\left(1.7 \times 10^{6} \pm 0.05 \times 10^{6} \mathrm{~g} / \mathrm{mol}\right)$ beta-glucan was $97.4 \pm 0.7 \%$, and the purity of low molar mass $\left(5.9 \times 10^{4} \pm 0.3 \times 10^{4} \mathrm{~g} / \mathrm{mol}\right)$ beta-glucan was $99.1 \pm 0.3 \%$. Both fractions of these polysaccharides were used as a $1 \%$ addition to the semisynthetic rat's feed.

Table 4. Physicochemical characteristics of beta-glucan fractions.

\begin{tabular}{ccccccc}
\hline $\begin{array}{c}\text { BG } \\
\text { Fraction }\end{array}$ & $\begin{array}{c}\text { Molar Mass } \\
(\mathrm{g} / \mathrm{mol})\end{array}$ & $\begin{array}{c}\text { Purity } \\
\mathbf{( \% )}\end{array}$ & $\begin{array}{c}\text { TPC } \\
\text { (GAE/ } \\
\mathbf{1} \text { g d.b) }\end{array}$ & $\begin{array}{c}\text { DPPH } \\
(\boldsymbol{\mu m o l} \\
\text { of Trolox) }\end{array}$ & $\begin{array}{c}\text { Soluble } \\
\text { Proteins } \\
\mathbf{( \% / d b )}\end{array}$ & $\begin{array}{c}\text { Nitrogen } \\
\times 5.83 \\
(\% / d b)\end{array}$ \\
\hline low & $\begin{array}{c}5.9 \times 10^{4} \pm \\
0.3 \times 10^{4}\end{array}$ & $99.1 \pm 0.3$ & 0.20 & 5.41 & $0.09 \pm 0.01$ & $1.14 \pm 0.14$ \\
high & $\begin{array}{c}1.7 \times 10^{6} \pm \\
0.05 \times 10^{6}\end{array}$ & $97.4 \pm 0.7$ & 0.48 & 6.03 & $0.70 \pm 0.14$ & $1.17 \pm 0.08$ \\
\hline
\end{tabular}

The beta-glucan fraction of low molar mass revealed high beta-glucan content with a neglible amount of soluble proteins and amine nitrogen. In addition, antioxidant activity was very low and within the range of interference caused by residual proteins, which means that no residual polyphenolic compounds were present in the fraction. The high molar mass beta-glucan fraction was characterized by a slightly higher TPC value, which was in accordance with higher soluble protein content; however, both values were still in very low and almost neglible levels. Such characteristics suggest quite different mechanisms of antioxidative activity of both beta-glucan fractions, which was observed in vivo.

\subsection{Animals and Experimental Design}

The experiment was performed on adult male Sprague-Dawley rats $(n=96)$ purchased from Charles River Laboratories (Charles River, Sulzfeld, Germany). Experimental details, animal's house conditions, and composition of experimental feeds were described in our previous paper [43].

Briefly, in colitis groups $(\mathrm{C}, \mathrm{n}=48)$ local colon inflammation was induced by TNBS (2,4,6,6-trinitrobenzenesulfonic acid) ethanol solution rectal administration, whereas in control groups $(\mathrm{H}, \mathrm{n}=48)$ (shame-operated), the same volume of $0.9 \% \mathrm{NaCl}$ was given. Then, rats from $\mathrm{C}$ and $\mathrm{H}$ groups were divided into 3 nutritional subgroups $(\mathrm{n}=8$ each) which received for 3 or 7 days after TNBS/ NaCl administration 3 types of feed differing in the addition of the oat beta-glucan fraction according to the group symbols below: $\mathrm{C} \beta \mathrm{Gl}+$ and $\mathrm{H} \beta \mathrm{Gl}+$ received for 3 or 7 days $\mathrm{AIN}-93 \mathrm{M}$ feed with $1 \%(w / w)$ low molar mass beta-glucan; $\mathrm{C} \beta \mathrm{Gh}+$ and $\mathrm{H} \beta \mathrm{Gh}+$ received for 3 or 7 days $\mathrm{AIN}-93 \mathrm{M}$ feed with $1 \%(w / w)$ high molar mass beta-glucan; $C \beta$ G- and H $\beta$ Gl- received for 3 or 7 days AIN-93M feed without beta-glucan Figure 5. Feed intake was measured every 2 days by calculating the standardized intake (g/day/100 g rat body weight); final body weight was measured $12 \mathrm{~h}$ before euthanasia. After 3 or 7 days of feeding, rats were introduced into deep anesthesia (Isoflurane inhalation), bled from the heart, and then, the large intestine was removed to determined the stage of inflammation. After assessing the location of macroscopic lesions in the large intestine, the damaged sections of the colon were excised, part of them were fixed in $4 \%$ buffered formaldehyde, and the remaining fragments were frozen in liquid nitrogen and stored in $-80^{\circ} \mathrm{C}$ until biochemical analysis. Details of tissue collection and preparation as well as morphological criteria (scores) of colitis severity and microscopic colonic tissues damage (scores) were described in our previous paper [43].

The animal experiment was conducted after the approval of the II Local Animal Care and Use Committee in Warsaw (Resolution \# 60/2015). All the procedures will be designed and conducted according to Polish and EU law regulations and with respect to $3 \mathrm{R}$ rules (Replacement, Reduction, and Refinement). 


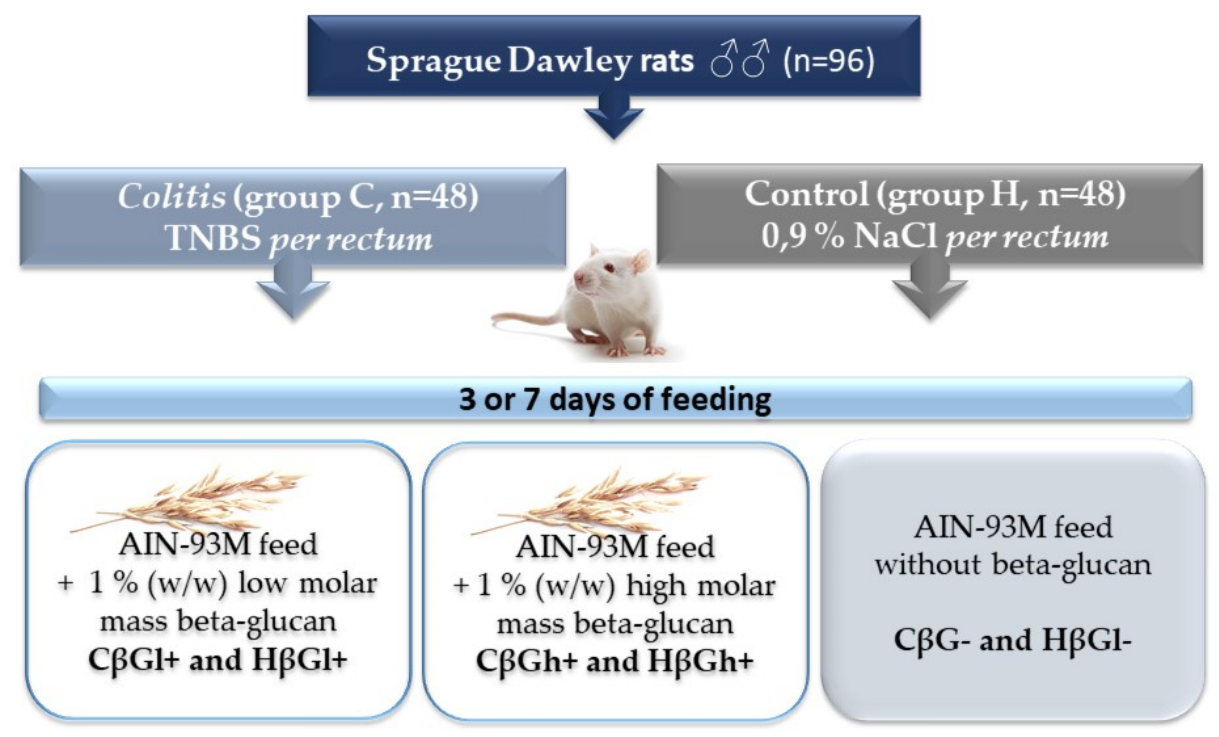

Figure 5. Scheme of experimental design of the study. TNBS: 2,4,6,-trinitrobenzenesulfonic acid alcohol solution.

\subsection{Evaluation of Histopathological Changes in the Wall of the Colon}

The collected macroscopically altered colon specimens after being fixed in $4 \%$ buffered formaldehyde were processed via standard protocols (dehydration, clearing, and paraffinization). Sections from each paraffin block were cut in $4 \mu \mathrm{m}$ thickness and stained with hematoxylin-eosin. The blinded slides were examined by a pathologist and the degree, extent, and type of inflammation, ulceration, and degree of regeneration/architectural distortion were assessed. Finally, microscopic score according to Galvez et al. (2001) was established for all rats [65].

\subsection{Determination of Inflammation Parameters}

The phosphate-buffered saline was used to homogenize colon tissue samples. In tissue homogenates, the concentration of pro- and anti-inflammatory cytokines (IL-1, IL-6, IL-10, and IL-12), tumor necrosis factor alpha (TNF- $\alpha$ ), C-reactive protein (CRP), prostaglandin E2 (PGE2), and thromboxane A2 (TXA2) were determined using a competitive specific enzyme immunoassay (ELISA) according to the manufacturer's instructions (DRG Instruments $\mathrm{GmbH}$, Marburg, Germany). In turn, the concentration of total cyclooxygenase (COX) and myeloperoxidase activity (MPO) were determined by enzymatic assay (Cayman Chemical, Ann Arbor, MI, USA).

\subsection{RNA Isolation, Reverse Transcription, and Real-Time PCR}

RNA isolation, reverse transcription, and real-time PCR methods were described prviously by Żyła et al. (2019) [43]. Briefly, total RNA from the colon samples was isolated using the RNeasy Lipid Tissue Mini Kit (Qiagen, Hilden, Germany) according to the manufacturer's instruction. The RNA concentration and purity were measured using a NanoDrop ${ }^{\mathrm{TM}} 2000$ spectrophotometer (Thermo Fisher Scientific, Waltham, MA, USA) that indicated RNA concentration and purity. The RNA integrity was assessed using an Agilent Bioanalyzer 2100 system with the RNA 6000 Nano LabChip ${ }^{\circledR}$ kit (Agilent Technologies, Palo Alto, CA, USA); minimal acceptable RNA integrity (RIN) was 9. Then, RNA was converted using an RT2 First Strand Kit (Qiagen, Hilden, Germany) to complementary DNA (cDNA) and prepared by RT-PCR assay according to the manufacturer's protocol. The expression profiling was performed using the $\mathrm{RT}^{2}$ Profiler ${ }^{\mathrm{TM}}$ PCR Rat Inflammatory Cytokines and Receptors array (Qiagen, Hilden, Germany) based on the manufacturer's instructions, in one technical replicates for each colon sample. PCR reactions, with an initial 10-min step at $95^{\circ} \mathrm{C}$ followed by 40 cycles of $95^{\circ} \mathrm{C}$ for $15 \mathrm{~s}$ and $60^{\circ} \mathrm{C}$ for $1 \mathrm{~min}$, 
were carried out on a Stratagene Mx3005P qPCR system (Agilent Technologies, Palo Alto, CA, USA). Relative gene expression was calculated using the $\Delta \Delta \mathrm{Ct}$ method with Ldha and Rplp1 as housekeeping genes using the Data Analysis Qiagen Center (Qiagen, Hilden, Germany). The results are shown as the relative gene expression of the target vs. reference gene in relation to the healthy control group (HßG-) calculated as 1.

\subsection{Statistical Analysis}

Results data are represented as mean \pm SE. Statistical analyses were performed with Statistica software version 13.0 (StatSoft Inc.,Tulsa, OK, USA). Using a two-way analysis of variance (ANOVA), we compared differences between groups, which was then followed by a post hoc Tukey's test. Differences were considered as significant at $p<0.05, p<0.01$, $p<0.001$.

\section{Conclusions}

Our results indicate that the therapeutic effect of oat beta-glucans depends on their molar mass and stage of $\mathrm{CD}$. The consumption of low molar mass beta-glucans reduce the gene expression of pro-inflammatory cytokines and their protein concentration in the colon, suggesting effects at both the tissue and molecular levels, which is a good prognostic for use in $\mathrm{CD}$ dietotherapy. Meanwhile, high molecular mass beta-glucan, due to its higher viscosity improved the tissue recovery potential that results in apparently better histological response. The neutrality of beta-glucan in the normal colon and high activity in colitis prove that this substance is safe for the organism.

Supplementary Materials: The following are available online at https://www.mdpi.com/article/10 .3390/ijms22094485/s1. Table S1: Changes in gene expression 3 and 7 days after TNBS administration. Regulation of genes encode inflammatory cytokines and their receptors in the colon tissue. Results are reported as fold regulation $>2$; bold means statistical significance in Student's $t$-test $p \leq 0.05$.

Author Contributions: Conceptualization, K.D., J.H. and J.G.-O.; methodology, J.H., R.S., J.W., D.K., E.Ż., K.D., and J.G.-O.; formal analysis, E.Ż., K.D., J.H., and J.G.-O.; investigation, E.Ż., J.H., R.S., J.W., D.K., K.D., and J.G.-O.; resources, E.Ż., J.H., J.W., D.K., and J.G.-O.; data curation, E.Ż., K.D., and J.G.-O. writing—original draft preparation, E.Ż., K.D., and J.G.-O.; writing—review and editing, E.Ż., K.D., J.W., J.H., R.S., and D.K.; visualization, E.Ż. and K.D.; supervision, J.G.-O., K.D., J.H., R.S., and J.W.; project administration, E.Ż., K.D., and J.G.-O.; funding acquisition, J.G.-O. Authorship must be limited to those who have contributed substantially to the work reported. All authors have read and agreed to the published version of the manuscript.

Funding: The authors acknowledge the financial support of the National Science Centre, Poland through grant number 2015/17/B/NZ9/01740.

Institutional Review Board Statement: The animal experiment was conducted after the approval of the II Local Animal Care and Use Committee in Warsaw (Resolution \# 60/2015; 29 June 2015).

Informed Consent Statement: Not applicable.

Data Availability Statement: The data that support the findings of this study are available on request from the corresponding author [K.D.].

Acknowledgments: We would like to acknowledge Michał Oczkowski, Tomasz Królikowski, and Łukasz Kopiasz, from Department of Dietetic, Institute of Human Nutrition Sciences, WULS for excellent technical assistance in the animal experiment.

Conflicts of Interest: The authors declare no conflict of interest. The funders had no role in the design of the study; in the collection, analyses, or interpretation of data; in the writing of the manuscript, or in the decision to publish the results. 


\section{References}

1. Molodecky, N.A.; Soon, I.S.; Rabi, D.M.; Ghali, W.A.; Ferris, M.; Chernoff, G.; Benchimol, E.I.; Panaccione, R.; Ghosh, S.; Barkema, H.W.; et al. Increasing incidence and prevalence of the inflammatory bowel diseases with time, based on systematic review. Gastroenterology 2012, 142, 46-54. [CrossRef]

2. Gajendran, M.; Loganathan, P.; Jimenez, G.; Catinella, A.P.; Ng, N.; Umapathy, C.; Ziade, N.; Hashash, J.G. A comprehensive review and update on ulcerative colitis. Dis. Mon. 2019, 65, 100851. [CrossRef] [PubMed]

3. Abraham, C.; Cho, J.H. Inflammatory Bowel Disease. N. Engl. J. Med. 2009, 361, 2066-2078. [CrossRef]

4. Ananthakrishnan, A.N.; Kaplan, G.G.; Ng, S.C. Changing Global Epidemiology of Inflammatory Bowel Diseases: Sustaining Health Care Delivery Into the 21st Century. Clin. Gastroenterol. Hepatol. 2020, 18, 1252-1260. [CrossRef]

5. Feuerstein, J.D.; Cheifetz, A.S. Crohn Disease: Epidemiology, Diagnosis, and Management. Mayo Clin. Proc. 2017, 92, 1088-1103. [CrossRef]

6. Le Berre, C.; Ananthakrishnan, A.N.; Danese, S.; Singh, S.; Peyrin-Biroulet, L. Ulcerative Colitis and Crohn's Disease Have Similar Burden and Goals for Treatment. Clin. Gastroenterol. Hepatol. 2020, 18, 14-23. [CrossRef]

7. Tun, G.S.Z.; Cripps, S.; Lobo, A.J. Crohn's disease: Management in adults, children and young people-concise guidance. Clin. Med. J. R. Coll. Physicians Lond. 2018, 18, 231-236. [CrossRef]

8. Słowińska-Solnica, K.; Pawlica-Gosiewska, D.; Gawlik, K.; Owczarek, D.; Cibor, D.; Pocztar, H.; Mach, T.; Solnica, B. Serum inflammatory markers in the diagnosis and assessment of Crohn's disease activity. Arch. Med. Sci. 2021, 17, 252-257. [CrossRef] [PubMed]

9. Vetvicka, V.; Vannucci, L.; Sima, P.; Richter, J. Beta glucan: Supplement or drug? From laboratory to clinical trials. Molecules 2019, 24, 1251. [CrossRef] [PubMed]

10. Bashir, K.M.I.; Choi, J.S. Clinical and physiological perspectives of $\beta$-glucans: The past, present, and future. Int. J. Mol. Sci. 2017, 18, 1906. [CrossRef] [PubMed]

11. Han, B.; Baruah, K.; Cox, E.; Vanrompay, D.; Bossier, P. Structure-Functional Activity Relationship of $\beta$-Glucans From the Perspective of Immunomodulation: A Mini-Review. Front. Immunol. 2020, 11, 658. [CrossRef]

12. Luo, J.; Cheng, L.; Du, Y.; Mao, X.; He, J.; Yu, B.; Chen, D. The anti-inflammatory effects of low- and high-molecular-weight beta-glucans from: Agrobacterium sp. ZX09 in LPS-induced weaned piglets. Food Funct. 2020, 11, 585-595. [CrossRef] [PubMed]

13. De Felice, B.; Damiano, S.; Montanino, C.; Del Buono, A.; La Rosa, G.; Guida, B.; Santillo, M. Effect of beta- and alpha-glucans on immune modulating factors expression in enterocyte-like Caco-2 and goblet-like LS 174T cells. Int. J. Biol. Macromol. 2020, 153, 600-607. [CrossRef] [PubMed]

14. Wilczak, J.; Błaszczyk, K.; Kamola, D.; Gajewska, M.; Harasym, J.P.; Jałosińska, M.; Gudej, S.; Suchecka, D.; Oczkowski, M.; Gromadzka-Ostrowska, J. The effect of low or high molecular weight oat beta-glucans on the inflammatory and oxidative stress status in the colon of rats with LPS-induced enteritis. Food Funct. 2015, 6, 590-603. [CrossRef]

15. Błaszczyk, K.; Wilczak, J.; Harasym, J.; Gudej, S.; Suchecka, D.; Kr, T.; Lange, E.; Gromadzka-Ostrowska, J. Impact of low and high molecular weight oat beta-glucan on oxidative stress and antioxidant defense in spleen of rats with LPS induced enteritis. Food Hydrocoll. 2015, 51, 272-280. [CrossRef]

16. Suchecka, D.; Harasym, J.; Wilczak, J.; Gromadzka-Ostrowska, J. Hepato- and gastro- protective activity of purified oat 1-3, 1-4- $\beta$-d-glucans of different molecular weight. Int. J. Biol. Macromol. 2016, 91, 1177-1185. [CrossRef] [PubMed]

17. Rosen, M.J.; Dhawan, A.; Saeed, S.A. Inflammatory bowel disease in children and adolescents. JAMA Pediatr. 2015, 169, 1053-1060. [CrossRef]

18. Roberts, S.E.; Thorne, K.; Thapar, N.; Broekaert, I.; Benninga, M.A.; Dolinsek, J.; Mas, E.; Miele, E.; Orel, R.; Pienar, C.; et al. A systematic review and meta-analysis of paediatric inflammatory bowel disease incidence and prevalence across Europe. J. Crohn's Colitis 2020, 14, 1119-1148. [CrossRef]

19. Te Velde, A.A.; Verstege, M.I.; Hommes, D.W. Critical appraisal of the current practice in murine TNBS-induced colitis. Inflamm. Bowel Dis. 2006, 12, 995-999. [CrossRef]

20. Antoniou, E.; Margonis, G.A.; Angelou, A.; Pikouli, A.; Argiri, P.; Karavokyros, I.; Papalois, A.; Pikoulis, E. The TNBS-induced colitis animal model: An overview. Ann. Med. Surg. 2016, 11, 9-15. [CrossRef] [PubMed]

21. Parra, R.S.; Lopes, A.H.; Carreira, E.U.; Feitosa, M.R.; Cunha, F.Q.; Garcia, S.B.; Cunha, T.M.; Da Rocha, J.J.R.; Féres, O. Hyperbaric oxygen therapy ameliorates TNBS-induced acute distal colitis in rats. Med. Gas Res. 2015, 5, 6. [CrossRef]

22. Catana, C.S.; Magdas, C.; Tabaran, F.A.; Craciun, E.C.; Deak, G.; Magdas, V.A.; Cozma, V.; Gherman, C.M.; Berindan-Neagoe, I.; Dumitrascu, D.L. Comparison of two models of inflammatory bowel disease in rats. Adv. Clin. Exp. Med. 2018, 27, 599-607. [CrossRef]

23. Brenna, Ø.; Furnes, M.W.; Drozdov, I.; van Beelen Granlund, A.; Flatberg, A.; Sandvik, A.K.; Zwiggelaar, R.T.M.; Mårvik, R.; Nordrum, I.S.; Kidd, M.; et al. Relevance of TNBS-Colitis in Rats: A Methodological Study with Endoscopic, Historical and Transcripttomic Characterization and Correlation to IBD. PLoS ONE 2013, 8, e54543. [CrossRef]

24. Alex, P.; Zachos, N.C.; Nguyen, T.; Gonzales, L.; Chen, T.E.; Conklin, L.S.; Centola, M.; Li, X. Distinct cytokine patterns identified from multiplex profiles of murine DSS and TNBS-induced colitis. Inflamm. Bowel Dis. 2009, 15, 341-352. [CrossRef]

25. Chamouard, P.; Richert, Z.; Meyer, N.; Rahmi, G.; Baumann, R. Diagnostic Value of C-Reactive Protein for Predicting Activity Level of Crohn's Disease. Clin. Gastroenterol. Hepatol. 2006, 4, 882-887. [CrossRef] [PubMed] 
26. Vermeire, S.; Van Assche, G.; Rutgeerts, P. C-Reactive Protein as a Marker for Inflammatory Bowel Disease. Inflamm. Bowel Dis. 2004, 10, 661-665. [CrossRef]

27. Plata-Salamán, C.R. Cytokines and feeding. Int. J. Obes. 2001, 25, S48-S52. [CrossRef] [PubMed]

28. Danese, S.; Grisham, M.; Hodge, J.; Telliez, J.-B. JAK inhibition using tofacitinib for inflammatory bowel disease treatment: A hub for multiple inflammatory cytokines. Am. J. Physiol. Gastrointest. Liver Physiol. 2016, 310, G155-G162. [CrossRef] [PubMed]

29. Chen, L.; Deng, H.; Cui, H.; Fang, J.; Zuo, Z.; Deng, J.; Li, Y.; Wang, X.; Zhao, L. Inflammatory responses and inflammationassociated diseases in organs. Oncotarget 2018, 9, 7204-7218. [CrossRef]

30. Macaluso, F.S.; Orlando, A.; Cottone, M. Anti-interleukin-12 and anti-interleukin-23 agents in Crohn's disease. Expert Opin. Biol. Ther. 2019, 19, 89-98. [CrossRef] [PubMed]

31. Zhu, L.; Gu, P.Q.; Shen, H. Protective effects of berberine hydrochloride on DSS-induced ulcerative colitis in rats. Int. Immunopharmacol. 2019, 68, 242-251. [CrossRef]

32. Shoukat, M.; Sorrentino, A. Cereal $\beta$-glucan: A promising prebiotic polysaccharide and its impact on the gut health. Int. J. Food Sci. Technol. 2021, ijfs.14971. [CrossRef]

33. Christophi, G.P.; Rong, R.; Holtzapple, P.G.; Massa, P.T.; Landas, S.K. Immune markers and differential signaling networks in ulcerative colitis and Crohn's disease. Inflamm. Bowel Dis. 2012, 18, 2342-2356. [CrossRef]

34. Yang, J.; Li, Y.; Zhang, X. Meta-analysis of macrophage migration inhibitory factor (MIF) gene-173G/C polymorphism and inflammatory bowel disease (IBD) risk. Int. J. Clin. Exp. Med. 2015, 8, 9570.

35. Cui, G.; Olsen, T.; Christiansen, I.; Vonen, B.; Florholmen, J.; Goll, R. Improvement of real-time polymerase chain reaction for quantifying TNF- $\alpha$ mRNA expression in inflamed colorectal mucosa: An approach to optimize procedures for clinical use. Scand. J. Clin. Lab. Investig. 2006, 66, 249-259. [CrossRef] [PubMed]

36. Theiss, A.L.; Simmons, J.G.; Jobin, C.; Lund, P.K. Tumor necrosis factor (TNF) $\alpha$ increases collagen accumulation and proliferation in intestinal myofibroblasts via TNF receptor 2. J. Biol. Chem. 2005, 280, 36099-36109. [CrossRef] [PubMed]

37. Frank, D.N.; Amand, A.L.S.; Feldman, R.A.; Boedeker, E.C.; Harpaz, N.; Pace, N.R. Molecular-phylogenetic characterization of microbial community imbalances in human inflammatory bowel diseases. Proc. Natl. Acad. Sci. USA 2007, 104, 13780-13785. [CrossRef] [PubMed]

38. Neumann, C.; Scheffold, A.; Rutz, S. Functions and regulation of T cell-derived interleukin-10. Semin. Immunol. 2019, 44, 101344. [CrossRef]

39. Mitsuyama, K.; Tomiyasu, N.; Takaki, K.; Masuda, J.; Yamasaki, H.; Kuwaki, K.; Takeda, T.; Kitazaki, S.; Tsuruta, O.; Sata, M. Interleukin-10 in the Pathophysiology of Inflammatory Bowel Disease: Increased Serum Concentrations During the Recovery Phase. Mediat. Inflamm. 2006, 2006, 026875. [CrossRef]

40. Hugot, J.P.; Chamaillard, M.; Zouali, H.; Lesage, S.; Cézard, J.P.; Belaiche, J.; Almer, S.; Tysk, C.; O'morain, C.A.; Gassull, M.; et al. Association of NOD2 leucine-rich repeat variants with susceptibility to Crohn's disease. Nature 2001, 411, 599-603. [CrossRef]

41. Ogura, Y.; Bonen, D.K.; Inohara, N.; Nicolae, D.L.; Chen, F.F.; Ramos, R.; Britton, H.; Moran, T.; Karaliuskas, R.; Duerr, R.H.; et al. A frameshift mutation in NOD2 associated with susceptibility to Crohn's disease. Nature 2001, 411, 603-606. [CrossRef] [PubMed]

42. Bernstein, C.N.; Fried, M.; Krabshuis, J.H.; Cohen, H.; Eliakim, R.; Fedail, S.; Gearry, R.; Goh, K.L.; Hamid, S.; Khan, A.G.; et al. World gastroenterology organization practice guidelines for the diagnosis and management of IBD in 2010. Inflamm. Bowel Dis. 2010, 16, 112-124. [CrossRef]

43. Żyła, E.; Dziendzikowska, K.; Gajewska, M.; Wilczak, J.; Harasym, J.; Gromadzka-Ostrowska, J. Beneficial effects of oat beta-glucan dietary supplementation in colitis depend on its molecular weight. Molecules 2019, 24, 3591. [CrossRef] [PubMed]

44. Arena, M.P.; Russo, P.; Capozzi, V.; Rascón, A.; Felis, G.E.; Spano, G.; Fiocco, D. Combinations of cereal $\beta$-glucans and probiotics can enhance the anti-inflammatory activity on host cells by a synergistic effect. J. Funct. Foods 2016, 23, 12-23. [CrossRef]

45. Shi, L.; Lin, Q.; Yang, T.; Nie, Y.; Li, X.; Liu, B.; Shen, J.; Liang, Y.; Tang, Y.; Luo, F. Oral administration of: Lentinus edodes $\beta$-glucans ameliorates DSS-induced ulcerative colitis in mice via MAPK-Elk-1 and MAPK-PPAR $\gamma$ pathways. Food Funct. 2016, 7 , 4614-4627. [CrossRef]

46. Liu, B.; Lin, Q.; Yang, T.; Zeng, L.; Shi, L.; Chen, Y.; Luo, F. Oat $\beta$-glucan ameliorates dextran sulfate sodium (DSS)-induced ulcerative colitis in mice. Food Funct. 2015, 6, 3454-3463. [CrossRef] [PubMed]

47. Crespo, H.; Guillén, H.; de Pablo-Maiso, L.; Gómez-Arrebola, C.; Rodríguez, G.; Glaria, I.; de Andrés, D.; Reina, R. Lentinula edodes $\beta$-glucan enriched diet induces pro-and anti-inflammatory macrophages in rabbit. Food Nutr. Res. 2017, 61, 1412791. [CrossRef]

48. Mikkelsen, M.S.; Jespersen, B.M.; Mehlsen, A.; Balling Engelsen, S.; Frøkiaer, H. Cereal $\beta$-glucan immune modulating activity depends on the polymer fine structure. FRIN 2014, 62, 829-836. [CrossRef]

49. Kopiasz, Ł.; Dziendzikowska, K.; Gajewska, M.; Oczkowski, M.; Majchrzak-Kuligowska, K.; Królikowski, T.; Gromadzkaostrowska, J. Effects of dietary oat beta-glucans on colon apoptosis and autophagy through tlrs and dectin-1 signaling pathwayscrohn's disease model study. Nutrients 2021, 13, 321. [CrossRef]

50. Peterson, C.G.B.; Eklund, E.; Taha, Y.; Raab, Y.; Carlson, M. A new method for the quantification of neutrophil and eosinophil cationic proteins in feces: Establishment of normal levels and clinical application in patients with inflammatory bowel disease. Am. J. Gastroenterol. 2002, 97, 1755-1762. [CrossRef]

51. Masoodi, I.; Dutta, U.; Vaiphei, K.; Kochhar, R.; Vaishnavi, C.; Hussain, S.; Prasad, K.K.; Singh, K. Evaluation of fecal myeloperoxidase as a biomarker of disease activity and severity in ulcerative colitis. Dig. Dis. Sci. 2012, 57, 1336-1340. [CrossRef] 
52. Pattison, D.; Davies, M. Reactions of Myeloperoxidase-Derived Oxidants with Biological Substrates:Gaining Chemical Insight into Human Inflammatory Diseases. Curr. Med. Chem. 2006, 13, 3271-3290. [CrossRef]

53. Reshetnikov, V.; Hahn, J.; Maueröder, C.; Czegley, C.; Munoz, L.E.; Herrmann, M.; Hoffmann, M.H.; Mokhir, A. Chemical tools for targeted amplification of reactive oxygen species in neutrophils. Front. Immunol. 2018, 9, 1. [CrossRef]

54. Harasym, J.; Zyła, E.; Dziendzikowska, K.; Gromadzka-Ostrowska, J. Proteinaceous residue removal from oat $\beta$-glucan extracts obtained by alkalinewater extraction. Molecules 2019, 24, 1729. [CrossRef] [PubMed]

55. Heinsbroek, S.E.M.; Williams, D.L.; Welting, O.; Meijer, S.L.; Gordon, S.; de Jonge, W.J. Orally delivered $\beta$-glucans aggravate dextran sulfate sodium (DSS)-induced intestinal inflammation. Nutr. Res. 2015, 35, 1106-1112. [CrossRef]

56. Ganda Mall, J.-P.; Casado-Bedmar, M.; Winberg, M.E.; Brummer, R.J.; Schoultz, I.; Keita, Å. V A $\beta$-Glucan-Based Dietary Fiber Reduces Mast Cell-Induced Hyperpermeability in Ileum From Patients With Crohn's Disease and Control Subjects. Inflamm. Bowel Dis. 2017, 24, 166-178. [CrossRef]

57. Armstrong, H.; Mander, I.; Zhang, Z.; Armstrong, D.; Wine, E. Not All Fibers Are Born Equal; Variable Response to Dietary Fiber Subtypes in IBD. Front. Pediatr. 2021, 8, 620189. [CrossRef] [PubMed]

58. Jin, Y.; Li, P.; Wang, F. $\beta$-glucans as potential immunoadjuvants: A review on the adjuvanticity, structure-activity relationship and receptor recognition properties. Vaccine 2018, 36, 5235-5244. [CrossRef] [PubMed]

59. Vetvicka, V.; Vetvickova, J. Anti-infectious and Anti-tumor Activities of $\beta$-glucans. Anticancer Res. 2020, 40, 3139-3145. [CrossRef]

60. Choromanska, A.; Kulbacka, J.; Harasym, J.; Oledzki, R.; Szewczyk, A.; Saczko, J. High- and low-Molecular Weight oat BetaGlucan Reveals Antitumor Activity in Human Epithelial Lung Cancer. Pathol. Oncol. Res. 2018, 24, 583-592. [CrossRef]

61. Choromanska, A.; Kulbacka, J.; Rembialkowska, N.; Pilat, J.; Oledzki, R.; Harasym, J.; Saczko, J. Anticancer properties of low molecular weight oat beta-glucan-An in vitro study. Int. J. Biol. Macromol. 2015, 80, 23-28. [CrossRef]

62. Pan, W.; Hao, S.; Zheng, M.; Lin, D.; Jiang, P.; Zhao, J.; Shi, H.; Yang, X.; Li, X.; Yu, Y. Oat-Derived $\beta$-Glucans Induced Trained Immunity Through Metabolic Reprogramming. Inflammation 2020, 43, 1323-1336. [CrossRef] [PubMed]

63. Harasym, J.; Olędzki, R. The Mutual Correlation of Glucose, Starch, and Beta-Glucan Release During Microwave Heating and Antioxidant Activity of Oat Water Extracts. Food Bioprocess Technol. 2018, 11, 874-884. [CrossRef]

64. Harasym, J.; Suchecka, D.; Gromadzka-Ostrowska, J. Effect of size reduction by freeze-milling on processing properties of beta-glucan oat bran. J. Cereal Sci. 2015, 61, 119-125. [CrossRef]

65. Gálvez, J.; Coelho, G.; Crespo, M.E.; Cruz, T.; Rodríguez-Cabezas, M.E.; Concha, A.; Gonzalez, M.; Zarzuelo, A. Intestinal anti-inflammatory activity of morin on chronic experimental colitis in the rat. Aliment. Pharmacol. Ther. 2001, 15, $2027-2039$. [CrossRef] [PubMed] 